\title{
Weather Factors Associated with Extremely Large Fires and Fire Growth Days
}

\author{
BRian E. POTTER ${ }^{\mathrm{a}}$ AND DANIEl MCEvoy ${ }^{\mathrm{b}}$ \\ ${ }^{\text {a }}$ Pacific Wildland Fire Sciences Laboratory, USDA Forest Service, Seattle, Washington \\ ${ }^{\mathrm{b}}$ Desert Research Institute, Reno, Nevada
}

(Manuscript received 19 March 2021, in final form 31 July 2021)

\begin{abstract}
Megafires" are of scientific interest and concern for fire management, public safety planning, and smokerelated public health management. There is a need to predict them on time scales from days to decades. Understanding is limited, however, of the role of daily weather in determining their extreme size. This study examines differences in the daily weather during these and other smaller fires, and in the two sets of fires' responses to daily weather and antecedent atmospheric dryness. Twenty fires of unusual size (over $36400 \mathrm{ha}$ ), were each paired with a nearby large fire (10 100-30 300 ha). Antecedent dryness and daily near-surface weather were compared for each set of fires. Growth response to daily weather was also examined for differences between the two sets of fires. Antecedent dryness measured as the evaporative demand drought index was greater for most of the fires of unusual size than it was for smaller fires. There were small differences in daily weather, with those differences indicating weather less conducive to fire growth for the unusually large fires than the smaller fires. Growth response was similar for the two sets of fires when weather properties were between 40th and 60th percentiles for each fire pair, but the unusually large fires' growth was observably greater than the smaller fires' growth for weather properties between the 80th to 100th percentiles. Response differences were greatest for wind speed, and for the Fosberg fire weather index and variants of the hot-dry-windy index, which combine wind speed with atmospheric moisture.
\end{abstract}

SIGNIFICANCE STATEMENT: Some wildfires grow substantially larger, and more rapidly, than the vast majority of others. This growth makes them more difficult to manage and increases their potential to cause injury, death, or property damage. We looked at how the growth of these fires relates to daily weather, either with more fire-conducive weather or with a different growth response to the weather. We found evidence suggesting that it is the growth response, not the weather itself, that differs. Results consistently pointed to high wind events as being related to disproportionate fire growth. Our results could help improve planning for these types of events both in the short term and in terms of climate impacts on fire.

KEYWORDS: Wildfires; Diurnal effects; Forest fires

\section{Introduction}

How do fires like Chetco Bar (77371 ha) or Milford Flat (146922 ha) become so big? Can we identify factors that made these fires blow up, or grow so large, while other fires like Taylor Creek (19525 ha) and Brian Head (28964 ha)-sizeable fires that occurred in the same general areas as the first two, respectively_did not achieve comparable size? Is it just chance, or are there common factors that drive these exceptionally large fires and differentiate them from other fires? Such factors could be related to the fire behavior triangle: fuels, weather, topography. They could be management based, such as resource availability or proximity to values at risk. They could also be a consequence of historic fuel management, prior fire occurrence, or landscape heterogeneity. Any attempt to prepare for these larger fires, or any effort to understand how often such fires might occur in the future, requires understanding what factors contribute to their ultimate size.

Corresponding author: Brian Potter, brian.potter@usda.gov

Earth Interactions is published jointly by the American Meteorological Society, the American Geophysical Union, and the Association of American Geographers.
The "largest of the large" fires are often referred to as "megafires." (See Tedim et al. (2018) for a discussion of this and related terms currently applied to extremely large fires.) Studies that seek to understand how these fires become so large tend to fall into two categories. The first category looks at individual fires as case studies, identifying factors that drove the fires' growth or intensity. This category includes analyses of the King Fire by Coen et al. (2018), Black Saturday by Cruz et al. (2012), and the Rim Fire by Peterson et al. (2015). This approach can be used to examine individual days' behavior and how that behavior relates to the weather, fuels, or topography, but the limited amount of data and inability to generalize results to other fires limit the insights gained.

The second category comprises studies that look at large numbers of fires and relationships between their size and the weather or climate. Stavros et al. (2014), Barbero et al. (2014), and Holden et al. (2018) are examples of this approach. The number of fires considered allows development of statistical models and general relationships. However, fire data amenable to this sort of study are limited to final size of the fires and their start dates. They necessarily ignored the possible impact of daily weather conditions (as well as variations in fuels and topography within the fire perimeter) and only addressed conditions associated with the start of the fire. Among the various start-day properties examined, these studies concluded that antecedent 
dryness, in a variety of measures, influences the probability a fire will become a large fire. (Exact terminology and size used for "large fire" vary across the studies.) While they did not look at individual fires based on start date, Balling et al. (1992) and Littell et al. (2009) examined the role of antecedent drought on fire season area burned, and found drought statistically explained roughly one-third of the area burned variability.

Prevailing climate, specifically some aspect of antecedent dryness, is clearly a major factor in fire growth, but practical experience and research both establish the importance of daily weather on fire growth. Fire tools such as BEHAVE and FARSITE, and the operational positions for fire behavior analysts (FBANs) and incident meteorologists (IMETs) evolved because operational planning depends on the daily weather. Abatzoglou and Kolden (2011) found that "antecedent climate exhibited no discernible influence on eventual fire size" for fires in Alaska, and that weather conditions during the fire's lifetime were more influential. Riley et al. (2013) similarly found that shorter-term weather had more impact on fire area, primarily through influence on fuel moisture, in the western United States. Sedano and Randerson (2014) concluded that daily vapor pressure deficit (VPD) was a factor driving fire growth probability in Alaska, also. These studies did not specifically look at megafires or any other subrange of the fire size spectrum.

The existing body of work shows that climate is part of the picture, and these latter studies show that daily weather determines daily growth for fires, generally. Unanswered is the question of what, if any, daily weather factors determine which fires become the "largest of the large" wildfires? Answering this requires examining the daily growth of multiple fires, using a uniform approach, which the case studies do not do. It requires accurate daily growth data, which the studies using only start date and final size lack.

Examination of the 21 fires identified in Larkin et al. (2015) as "very large fires" found that three criteria applied to all 21 of the fires on the list but were strict enough that few other fires met them. These criteria were as follows:

1) Final size over 36400 ha (90000 acres).

2) At least one growth event where the scaled circle-equivalent growth rate (described in the data section below as $L_{s}$ ) exceeded 2.5 .

3) The fire grew at least 8900 ha (22 000 acres) after the growth event described in criterion 2.

To distinguish these from "megafires," we refer to fires meeting these three criteria as "fires of unusual size" (FOUS, singular and plural).

The present study considers the following basic question: are one or more components of daily weather driving FOUS growth? If so, is that because the weather is different from other days/fires, or because FOUS respond to that weather differently? We examine how several weather properties differ, or do not, during the course of fires in a set of FOUS in comparison with a set of smaller, analog fires. The analog fires are "large fires" (LF) that do not meet the criteria for FOUS but occurred in the same general regions as the FOUS. We also examine relationships between the weather components and daily fire growth for FOUS as they compare with LFs. We are unaware of any previous study to systematically and quantitatively compare daily weather properties with daily fire growth using multiple fires.

\section{Methods}

\section{a. Data}

Data used for this study are described in Potter (2018) with some changes. Data selection and preparation are repeated here because of these changes and for the convenience of the reader.

\section{1) FiRE SELECTION AND GROWTH DATA}

The initial set of FOUS was the subjective list in Larkin et al. (2015), fires that occurred between 2002 and 2013. We added several FOUS occurring between 2014 and 2017 to the Larkin et al. (2015) list and removed fires that did not meet all three criteria from the original list. We selected candidate FOUS to expand the geographic and temporal coverage. Fires prior to 2004 were removed from the study because the chosen atmospheric data (see below) were not available for dates before March 2004.

To reduce differences in growth response due to nonweather factors (e.g., fuels) in our comparison of FOUS and LFs, we sought LF pair members that were geographically as close as possible to the individual FOUS. By searching the ICS-209 incident reports and the Monitoring Trends in Burn Severity database (MTBS; https://www.mtbs.gov/viewer/index.html, accessed 7 June 2021) we identified the nearest candidates with final sizes between 10100 and 30300 ha. Geographic proximity does not guarantee similar fuels, terrain, management histories, or climate for members of a pair, but it is the best criterion for achieving similarity on these terms.

Initial daily fire growth data for all fires came from the ICS-209 reports (https:/famit.nwcg.gov/applications/SIT209, originally accessed 12 March 2021). Historically, these forms usually state the size of the fire on the previous evening, but that is not always the case. Furthermore, the majority of fires have days with missing ICS-209 reports, resulting in gaps in the record.

We collected progression maps, daily GIS shapefiles for each fire, and airborne infrared (IR) measurements from the National Infrared Operations (NIROPS) program (all available at https://ftp.wildfire.gov/, accessed 8 December 2020). For each fire, we tabulated daily size information from each of these sources and ICS-209 reports and considered any narrative commentary in the reports. For each day, we used the most likely, reliable, annotated size from among the sources. In rare instances, archived newspaper articles helped identify the exact day of particular growth events. Usually, the preferred source was the IR measurement. When the reconciled data showed no further growth, we designated the first day at that size as the final day and the fire's duration. (In rare instances, the final ICS-209 included a change in size, but these were typically less than 100 acres and we did not adjust for them.)

In some cases, the reconciled data for an FOUS no longer met all three FOUS criteria. We removed these fires from the study. If a FOUS's paired LF became unusable after reconciliation, we sought a new LF using the process described previously. Most often this was a result of administrative actions, such as adding a fire to a complex or substantial burnout operations. 


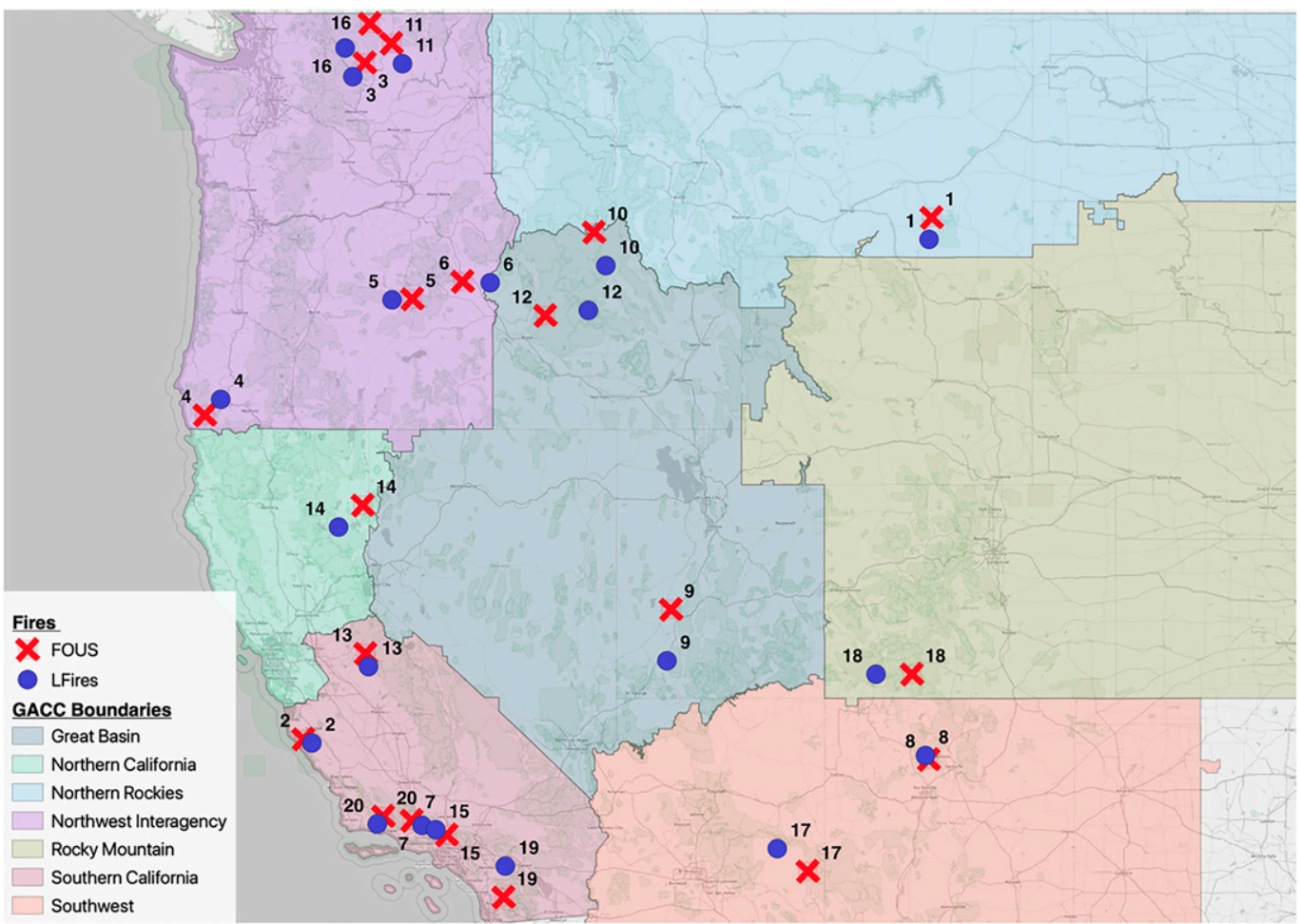

FIG. 1. Locations of all FOUS and LFs used in this study. Geographic area coordination center (GACC) boundaries are shown for reference with Fig. 2, below.

Because this study seeks to identify weather influences on fire growth, known human influences like burnouts would obscure the results. Since these often occur on days deemed manageable in terms of potential fire behavior, they result in burned acres on relatively moderate weather days, the opposite of the conditions of interest for this study. Ultimately, 20 fires were retained in each set. The FOUS set comprises 481 days of growth total, the LF set comprises 270 days. Figure 1 and Table 1 show and list the locations and dates of the fires after reconciliation.

Daily fire growth is reported in acres (converted to hectares here.) However, the significance of a given area growth depends heavily on fire size at the start of the day. A 1000 ha fire growing 200 ha in one day is very different from a 10000 ha fire growing 200 ha in one day. Furthermore, fires in different fuel types and fuel conditions grow at different rates for the same weather (e.g., grass vs heavy timber) and this makes direct comparison of area growth across fires problematic. To mitigate these factors, either of which would confound interpretation of weather influences, we examined three measures of growth. The first measure is daily area growth $\left(A\right.$, hectares day $\left.{ }^{-1}\right)$ equal to the total area on a given day $\left(A_{i}\right)$ minus the total area the previous day $\left(A_{i-1}\right)$. We also computed average daily growth for each fire and divided this into individual daily growth for that fire, yielding a scaled area growth rate ("scaled area," $A_{s}$, dimensionless):

$$
A_{s i}=\frac{D}{A_{f}}\left(A_{i}-A_{i-1}\right) \text {. }
$$

Here, $A_{s i}$ is the scaled area on day $i, A_{f}$ is the final fire area, $D$ is fire duration, and $A_{i}$ is fire area on day $i$.

For the third measure, we used a scaled circle-equivalent growth rate. We converted the area on each day to the radius of a circle with equal area, and computed the change in radius from the previous day. We then scaled this radial change by the individual fire's lifetime average radial growth rate, yielding a scaled linear growth rate ("scaled linear," $L_{s}$, dimensionless):

$$
L_{s i}=\frac{D}{\sqrt{A_{f}}}\left(\sqrt{A_{i}}-\sqrt{A_{i-1}}\right) .
$$

Dividing by lifetime average growth scales each fire's growth based on the average fuels, terrain, and management impacts, putting all fires on a more comparable scale. We implicitly assume that remaining variations in scaled growth due to these factors for a given fire are smaller than variation among fires due to them. Scaled area growth is more straightforward than scaled linear growth, with its assumption of constant shape. Since scaled area growth adjusts for fuels and terrain with fewer assumptions than scaled linear growth, results for scaled area will be discussed below. Because results for area and scaled linear growth may differ and add insight, they appear in the appendix.

\section{2) ATMOSPHERIC DATA}

To increase the relevance of this study to fire operations, we chose an atmospheric dataset that is operationally available and widely used, with broad coverage and relatively fine grid spacing. We used the North American Mesoscale Forecast 
TABLE 1. Names, dates, locations, and final sizes of the fires used in this study. Positive fire numbers are FOUS; negative numbers are the paired LFs.

\begin{tabular}{|c|c|c|c|c|c|c|}
\hline Fire No. & Name & Start & End & Lat & Lon & Size (ha) \\
\hline 1 & Ash Creek & 25 Jun 2012 & 7 Jul 2012 & 45.669 & -106.469 & 100994 \\
\hline 2 & Basin & 22 Jun 2008 & $25 \mathrm{Jul} 2008$ & 36.212 & -121.578 & 65890 \\
\hline 3 & Carlton Complex & 15 Jul 2014 & $30 \mathrm{Jul} 2014$ & 48.211 & -120.102 & 102289 \\
\hline 4 & Chetco Bar & 12 Jul 2017 & 25 Sep 2017 & 42.2491 & -123.954 & 77331 \\
\hline 5 & Canyon Creek & 12 Aug 2015 & 31 Aug 2015 & 44.284 & -118.961 & 42770 \\
\hline 6 & Cornet Windy Ridge & 11 Aug 2015 & 22 Aug 2015 & 44.585 & -117.752 & 41314 \\
\hline 7 & Day & 4 Sep 2006 & 1 Oct 2006 & 34.615 & -118.971 & 65843 \\
\hline 8 & Las Conchas & 26 Jun 2011 & 19 Jul 2011 & 35.812 & -106.541 & 63371 \\
\hline 9 & Milford Flat & $6 \mathrm{Jul} 2007$ & 12 Jul 2007 & 38.689 & -112.739 & 146922 \\
\hline 10 & Mustang Complex & 30 Jul 2012 & 12 Oct 2012 & 45.424 & -114.590 & 138195 \\
\hline 11 & Tunk Block [Okanogan] & 14 Aug 2015 & 29 Aug 2015 & 48.526 & -119.463 & 65432 \\
\hline 12 & Pioneer & 18 Jul 2016 & 18 Sep 2016 & 43.9981 & -115.762 & 76244 \\
\hline 13 & Rim & 17 Aug 2013 & 24 Sep 2013 & 37.857 & -120.086 & 104059 \\
\hline 14 & Rush & 13 Aug 2012 & 28 Aug 2012 & 40.621 & -120.152 & 127710 \\
\hline 15 & Station & 26 Aug 2009 & 7 Sep 2009 & 34.327 & -118.136 & 63244 \\
\hline 16 & Tripod Complex & 5 Jul 2006 & 18 Sep 2006 & 48.841 & -119.983 & 70827 \\
\hline 17 & Wallow & 30 May 2011 & 28 Jun 2011 & 33.602 & -109.449 & 217741 \\
\hline 18 & West Fork Complex & 6 Jun 2013 & 9 Jul 2013 & 37.462 & -106.943 & 43411 \\
\hline 19 & Witch & 21 Oct 2007 & 30 Oct 2007 & 33.079 & -116.766 & 100385 \\
\hline 20 & Zaca & 4 Jul 2007 & 12 Aug 2007 & 34.695 & -119.659 & 38247 \\
\hline-1 & Tongue River Complex & $8 \mathrm{Jul} 2017$ & 13 Jul 2017 & 45.3017 & -106.533 & 13332 \\
\hline-2 & Indians & 8 Jun 2008 & 6 Jul 2008 & 36.136 & -121.378 & 26630 \\
\hline-3 & Deep Harbor (PotPeak) & 26 Jul 2004 & 5 Aug 2004 & 47.991 & -120.394 & 11534 \\
\hline-4 & Taylor Creek Fire & 15 Jul 2018 & 12 Aug 2018 & 42.528 & -123.571 & 19525 \\
\hline-5 & South Fork Complex & 1 Aug 2014 & 22 Aug 2014 & 44.269 & -119.450 & 26760 \\
\hline-6 & Snake One & 28 Jul 2007 & 2 Aug 2007 & 44.563 & -117.090 & 10230 \\
\hline-7 & Ranch & 21 Oct 2007 & 26 Oct 2007 & 34.516 & -118.727 & 23634 \\
\hline-8 & Thompson Ridge & 31 May 2013 & 12 Jun 2013 & 35.892 & -106.620 & 9673 \\
\hline-9 & Brianhead & 17 Jun 2017 & 7 Jul 2017 & 37.7178 & -112.837 & 28964 \\
\hline-10 & Rabbit Foot & 2 Aug 2018 & 6 Sep 2018 & 44.856 & -114.307 & 14274 \\
\hline-11 & Columbia River Road & 7 Aug 2008 & 12 Aug 2008 & 48.198 & -119.199 & 8966 \\
\hline-12 & Valley Road & 3 Sep 2005 & 16 Sep 2005 & 44.086 & -114.728 & 16539 \\
\hline-13 & Telegraph & 25 Jul 2008 & 1 Aug 2008 & 37.607 & -120.015 & 13796 \\
\hline-14 & Moonlight & 3 Sep 2007 & 12 Sep 2007 & 40.220 & -120.736 & 26305 \\
\hline-15 & Sand & 22 Jul 2016 & 31 Jul 2016 & 34.431 & -118.398 & 16756 \\
\hline-16 & Crescent Mountain & 29 Jul 2018 & 4 Sep 2018 & 48.4514 & -120.579 & 19942 \\
\hline-17 & Cedar & 15 Jun 2016 & 26 Jun 2016 & 34.055 & -110.184 & 18295 \\
\hline-18 & 416 Fire & 1 Jun 2018 & 4 Jul 2018 & 37.461 & -107.808 & 21905 \\
\hline-19 & Mountain & 15 Jul 2013 & 25 Jul 2013 & 33.705 & -116.726 & 11141 \\
\hline-20 & Rey & 18 Aug 2016 & 27 Aug 2016 & 34.546 & -119.805 & 13359 \\
\hline
\end{tabular}

System (NAM) 218 grid (12 km grid spacing) 0000 UTC analysis, 0 -h forecast files for the dates of interest (downloaded from https:/www.ncdc.noaa.gov/data-access/model-data/ model-datasets/north-american-mesoscale-forecast-system-nam, link accessed 22 February 2021). Values at 0000 UTC were used as this time corresponds to late afternoon at most of the fire locations. We computed near-surface properties using model output temperatures and relative humidities $2 \mathrm{~m}$ above ground, and wind speeds $10 \mathrm{~m}$ above ground. Above-ground measures used values interpolated from pressure levels to geometric height.

\section{3) ATMOSPHERIC PROPERTIES}

Multiple atmospheric properties are known or suspected to influence fire growth, and there are several ways to quantify some of these properties. This paper focuses on eight nearsurface atmospheric properties, some closely related to each other. Table 2 shows the full list.

We examine temperature, moisture content (measured as relative humidity), and wind speed. In addition to these nearground values, we considered maximum wind speed and VPD in the lowest $500 \mathrm{~m}$ of the atmosphere. Maximum wind speed was obtained by comparing all model levels below $500 \mathrm{~m}$, and a $500 \mathrm{~m}$ value linearly interpolated in height from the model levels immediately above and below $500 \mathrm{~m}$. Maximum VPD was computed using the same process, applied to potential temperature and absolute vapor mixing ratio, then computing VPD at surface pressure while conserving potential temperature and mixing ratio to determine the level with the maximum VPD at surface pressure. These represent near-ground, but 
above-surface, conditions that could potentially influence the fire if this air were to mix down to the ground.

We also considered three fire-weather indices derived from these basic atmospheric properties. We used near-ground temperature, wind speed, and relative humidity to compute the Fosberg fire weather index (FFWI; Fosberg 1978). This uses wind speed and a fuel moisture derived from temperature and relative humidity to create a measure of fire weather. We computed a measure closely related to the Srock et al. (2018) hot-dry-windy index using maximum VPD and wind speed in the lowest $500 \mathrm{~m}$ of the model data. We refer to this measure as "HDW," and in addition to the maximum values, we also considered a version of HDW using surface values of wind speed and VPD. We include both of these versions because early testing during development of the HDW index (Potter et al. 2015) looked at the layer-maximum and surface-based versions of HDW and found that in some instances one worked better than the other, but which one worked better was not consistent.

We considered two measures of antecedent dryness, and how they each differ between the FOUS and LF. One measure is the sum of surface-based HDW over the 10 days before each fire's start, which we called HDW10. The other is the evaporative demand drought index (EDDI) of Hobbins et al. (2016). While HDW represents potential aerodynamic moisture flux, EDDI represents both this potential flux and the energy available at Earth's surface to evaporate moisture. Evaporative demand drought index is based on standardized anomalies in a physically based evaporative demand driven by temperature, wind speed, specific humidity, and incoming shortwave radiation at the surface. High EDDI values at shorter time scales (i.e., two weeks to one month) occurred at the start of several large fire case studies in California (McEvoy et al. 2019; Nauslar et al. 2019; Brown et al. 2020) and were also coincident with total area burned over time in California (McEvoy et al. 2020). For this study, the 2-week EDDI was obtained for the grid cell nearest each FOUS and LF for the start date of each fire. This represents the total evaporative demand in the two weeks leading up to each fire. Two-week EDDI data were obtained from NOAA's Physical Science Laboratory.

\section{b. Analysis}

The American Statistical Association issued a position paper (Wasserstein and Lazar 2016) strongly discouraging overuse or interpretation of significance tests, $p$ values, and inferential statistics. In the present study, we focus on visual interpretation of graphical results as a first point of reference on whether distributions of weather measures are similar or different for groups of fire growth days. Those differences are then further evaluated quantitatively using a two-sided Kolmogorov-Smirnov test. We used the R software package (R Core Team 2018) for the Kolmogorov-Smirnov tests and quantile regressions, as well as the boxplots and scatterplots presented here.

\section{1) BASIC FIRE PROPERTIES}

Before examining weather, we looked at several basic properties of the two sets of fires. Because fires were selected based on size, and partly on daily growth for FOUS (criterion
TABLE 2. Variable names for weather measures, with brief descriptions. Full descriptions are given in the text.

\begin{tabular}{cl}
\hline \hline Weather measure & \multicolumn{1}{c}{ Description } \\
\hline EDDI & $\begin{array}{c}\text { 2-week evaporative demand } \\
\text { drought index } \\
\text { 10-day sum of HDW_sfc values }\end{array}$ \\
HDW10 & 2 m above ground level air temperature \\
T_sfc & 2 m above ground level relative humidity \\
RH_sfc & 10 m above ground level wind speed \\
U_sfc & Max wind speed in lowest 500 m \\
U_max & Max water vapor pressure deficit in \\
VPD_max & lowest 500 m \\
& Fosberg fire weather index \\
FFWI & Hot-dry-windy computed from surface \\
HDW_sfc & values \\
HDW_max & Hot-dry-windy computed from 500-m \\
& max values \\
\hline
\end{tabular}

2), it is important to understand how the fire sets and their daily growth properties compare, and to consider this in interpreting the results. We examined the fire sets in terms of dates of occurrence within the year, fire durations, average daily growth, the fire-day of each fire's first growth spurt $\left(L_{s}>2.5\right)$, number of growth spurts, and duration of high-growth runs (consecutive days of growth spurts).

\section{2) ANTECEDENT CONDITIONS}

We examined EDDI and HDW10 with respect to the individual FOUS and LF pairs. The paired fires' dryness indices were examined using $x-y$ plots of each index. We also decomposed the EDDI values and plotted them the same way, in terms of the 2-week means of the driving variables: specific humidity, incoming shortwave radiation, wind speed, and daily maximum and minimum temperatures.

\section{3) DAILY WEATHER MEASURE CHARACTERISTICS}

Analysis of daily weather included two steps. First, the data were compared graphically as (LF, FOUS) pairs. The second step considered the daily weather values for all of the FOUS collectively and compared those with the collective daily values for all of the LFs. Despite the differing climes and the potential spread it introduces in the weather measures, this serves as a second comparison. Within this step, data are presented graphically as well as statistically using two-sided KolmogorovSmirnov testing.

\section{4) GROWTH RESPONSE TO WEATHER MEASURES}

Analysis of the fires' growth response to the weather involved two graphical and one quantitative components. The first component examined growth on (LF, FOUS) pairs for narrow, specified ranges of weather conditions. This is analogous to a medical dose-response investigation measuring the response (growth) of different groups, as the dose amount (weather property) varies. Other, unmeasured factors (e.g., fuel load or moisture, topography, past or current management actions) may influence response also, but being unmeasured or unknown, are treated as part of the residuals, error, or variance in the data. 
Quintile breakpoints (values for the 20th, 40th, 60th, and 80th percentile) were identified for each weather measure for all of the growth days in each fire pair. Looking only at days when a weather measure was in the third quintile (40th-60th percentile), representing "average" conditions, we compared mean fire growth for those days between the FOUS and LF in each pair. We repeated this process using fifth-quintile weather (greater than 80th percentile), representative of "extreme" conditions for that measure (for relative humidity, first quintile replaced fifth quintile because low values are the most fire conducive).

The second component used all FOUS growth days individually (ignoring which fire they were from) and compared these with all LF growth days (again, ignoring which fire they are from). On a given day, any of several weather or nonweather properties may be the limiting factor that determines a fire's growth. Quantile regression has been used in other studies to capture the effects of limiting factors in a complex process. Cade et al. (1999) observe that "changes near the maxima [of the dependent variable] are better estimates of the effects expected when the observed factor [independent variable] is the active limiting constraint." Conversely, changes in the dependent variable farther from the maxima may be more influenced by other factors. Therefore, we computed the 80th quantile regression of growth in each fire set as a function of individual daily weather properties to estimate the growth response when that property (not management, fuels, topography, or another weather property) is the most limiting factor. This addresses what the maximum potential influence of that weather property is on growth, and whether it appears to differ between FOUS and LFs.

The quantitative component focused on each fire's growth on outlier weather days, as compared with duration-average growth on each fire. This last step gives an indication of how important growth on "extreme" weather days is, as compared with more typical days, in each fire category. We used the outliers for each individual fire as determined by the standard boxplot definition, points more than 1.5 times the interquartile distance from the upper or lower quartile of the weather properties. High outliers were used for all weather properties except RH_sfc, for which low outliers were considered. Not all weather properties have outliers. For each fire, the average growth on the days of the weather outliers was divided by the average growth on all days. This ratio was then averaged over all fires that had outliers for a given weather property in a given fire set.

\section{Results}

\section{a. Basic fire properties}

The seasonal distribution of selected fires appears in Fig. 2, divided regionally for clarity. The most noteworthy points here are that within each region, the FOUS and LFs occurred at similar times of year, and that two regions had paired LFs occurring at the same time they had active FOUS. In several regions, FOUS extended later into the year than the chosen LFs. There may, however, be LFs that were not chosen for this study that extended as late in the year as the FOUS.

Figure 3 shows the durations of the paired FOUS and LFs, overlain on each other. Also indicated are the days on which
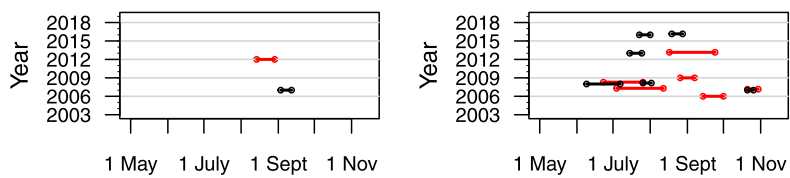

California - North
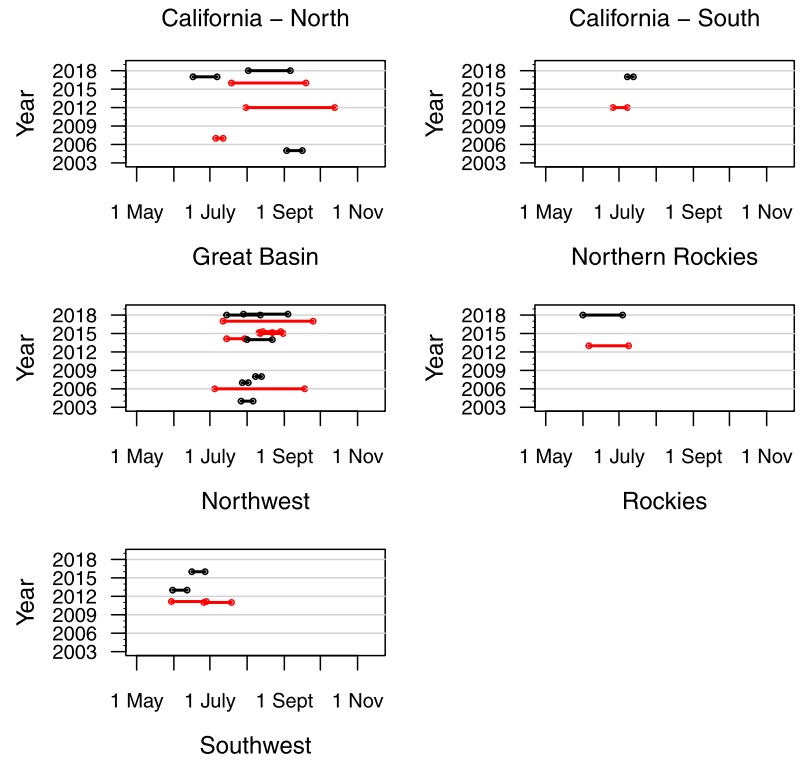

FIG. 2. Timing of FOUS (red) and LFs (black) within fire seasons, grouped geographically. Regions refer to the GACC boundaries shown in Fig. 1.

each FOUS met each of the three FOUS criteria. Durations for FOUS range from 7 to 76 days, and those for LFs range from 6 to 32 days. In 16 of the 20 pairs, the LF lasted longer than it took for the FOUS to become an FOUS.

We computed average daily growth in unscaled area $(A)$ on the fires two ways. Total fire size divided by duration provides an average that disregards gaps in the daily growth measurements, but is most representative of a fire's full lifetime. This "bulk" average yields 3346 ha across all FOUS and 1259 across the LFs. Alternatively, an average can be computed from individual daily size differences (e.g., $A_{i}-A_{i-1}$ ). This differs from the bulk average if there are any days of missing fire data. Figure 4 shows the latter mean daily growth on each fire, plotted as FOUS-LF pairs with a 1:1 diagonal for reference. Points above the 1:1 diagonal have higher values for the FOUS, points below have a higher value for the LF. Distance above (when FOUS exceeds LF) or to the right (when LF exceeds FOUS) for a point indicates the magnitude of the difference between pair members. Growth on almost all of the FOUS exceeds growth on their paired LFs, and the overall average across all FOUS is greater than that over all LFs. Scaled measures $A_{s}$ and $L_{s}$ arithmetically average to 1 on any given fire when there are no gaps in the record and are not shown.

With respect to the number of growth spurts and the duration of high-growth events, in both cases the highest values among the FOUS exceeded those among the LFs. The maximum number of spurts for an LF was four, while for FOUS it 


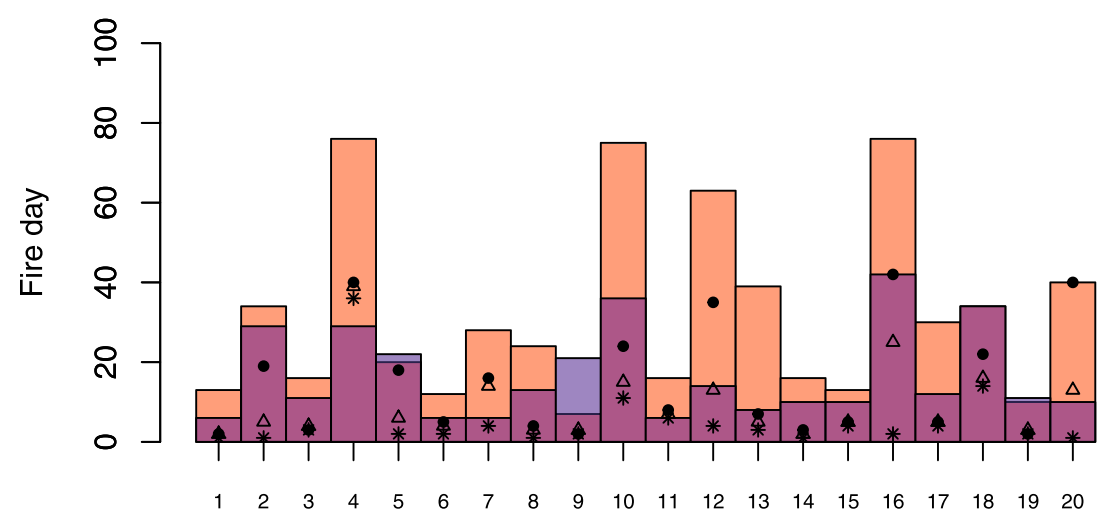

Fire Number

FIG. 3. Individual fire durations, and fire day on which each of the three FOUS criteria were met. Absolute value of fire number (Table 1) is shown on the $x$ axis, with FOUS (pink) and LF (blue) pair members overlain transparently. An asterisk in a column indicates the day on which the FOUS met the growth spike criterion. A triangle indicates the day on which it met the postspike growth criterion. A dot indicates the day on which it met the total size criterion.

was seven. Most fires had only 1 or 2 growth spurts (two LFs had no growth spurts). Three days was the longest growth run on an LF, while one FOUS had a five-day run. Most highgrowth events, in both sets, were just one day long.

\section{b. Antecedent conditions}

Paired values for HDW10 (Fig. 5a) show no strong clustering on one side or the other of the diagonal. Roughly half of the FOUS have higher values of HDW10 than their paired LFs. The centroid on the figure shows that, across the set of all pairs, the average HDW10 values are very similar for FOUS and LF fires. In contrast, EDDI (Fig. 5b) is higher for FOUS than LF for 16 of the 20 fire pairs. The centroid of all fire pairs also lies clearly in the FOUS half of the diagram. Both the individual pairs and the centroid indicate 2-week EDDI is often higher for FOUS than it is for their paired LF.

\section{c. Daily weather property characteristics}

\section{1) PAIRWISE COMPARISONS}

Paired plots (Fig. 6) for the direct weather properties indicate that weather was comparable between the two sets of fires. Since they are extremely similar to U_sfc and HDW_max, respectively, U_max and HDW_sfc are not shown. If anything, conditions were more favorable to fire development (i.e., higher temperatures, wind speeds, VPD and lower RH) for the LF members of pairs than they were for the FOUS members. The centroids on the plots are very close to the diagonal, however, indicating that these differences are small across all pairs. FFWI and HDW are also greater (more fire favorable) for the LF than the FOUS.

\section{2) Aggregate COMPARISON}

When weather is aggregated over all pairs within each fire set, the results suggest FOUS weather is less fire-conducive than LF weather, for most weather properties. Figure 7 shows box-and-whisker plots for all daily values of T_sfc, RH_sfc, U_sfc, VPD_max, FFWI, and HDW_max in each fire set. For most properties, the median value for FOUS was more moderate than for LF, though it still fell within the LF 25th-75th quantile range. For some properties there were no outliers, while others had numerous outlier values. High outliers were more common than low outliers. Outlier weather values will be discussed further in the section on growth response to the weather.

Aggregated fire-set weather properties were also compared using the two-sided Kolmogorov-Smirnov test. All weather properties yielded $\mathrm{p}$ values less than 0.01 , indicating there is a very low probability that the two samples (LF and FOUS) represent selections from the same parent distribution. Based

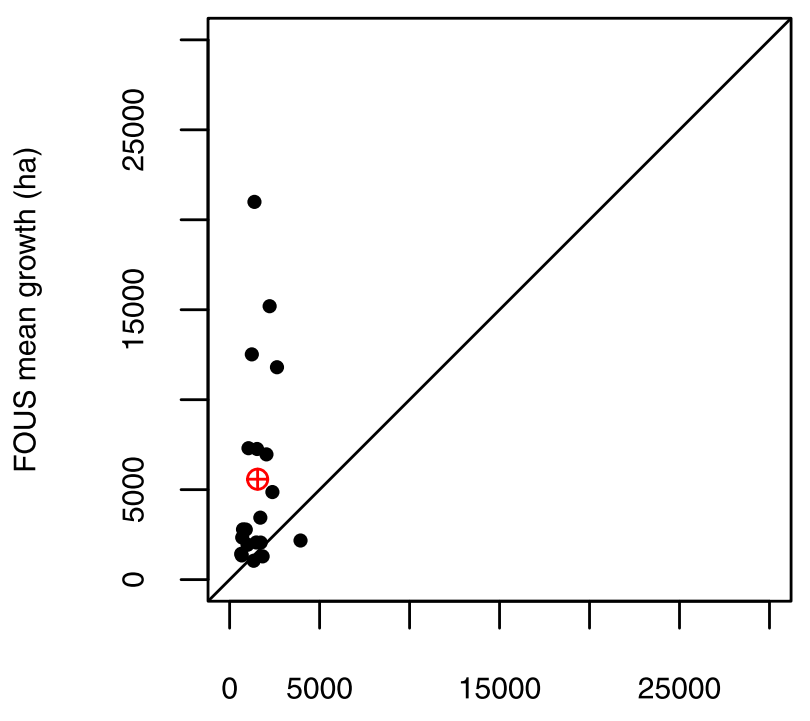

\section{LF mean growth (ha)}

FIG. 4. Average daily growth for (LF, FOUS) pairs. The diagonal 1:1 line is for reference, and the red open circle with cross hairs indicates the centroid of all fire pairs. 
(a)

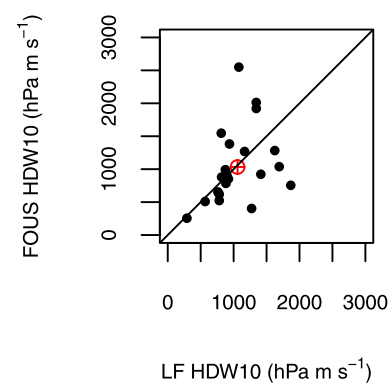

(b)

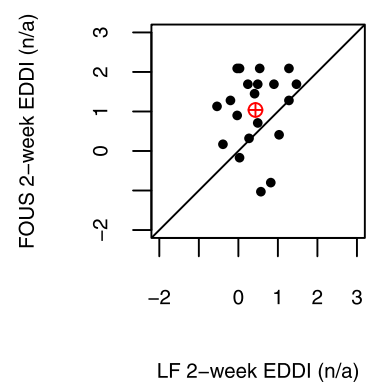

FIG. 5. Antecedent dryness measured as (a) HDW10 and (b) 2-week EDDI for paired fires. Each solid dot indicates one (LF, FOUS) pair; the red open circle with cross hairs indicates the centroid of all pairs. For centroids below the diagonal line, horizontal distance to the line is equal to the difference between LF and FOUS medians; for centroids above the diagonal, distance above the diagonal is equal to that difference.

on the box-and-whisker plots shown in Fig. 7, and on the empirical cumulative distributions produced by the KolmogorovSmirnov tests (not shown here), the daily weather properties were more moderate for the FOUS than for the LFs.

\section{d. Growth response to weather measures}

\section{1) PAIRWISE COMPARISON}

Fire-pair growth response $\left(A_{s}\right)$ to middle-quintile weather is shown in Fig. 8. The scatter and spread among the pairs and across the diagonal suggest no consistent difference in the way members of FOUS and LF pairs respond to comparable, middle-quintile weather conditions. The centroids also fall close to the diagonal, indicating that on average, there is little difference in the growth response to these weather conditions.

Figure 9 shows the response to comparable top-quintile (bottom quintile for $\mathrm{RH}$ ) weather for each pair. These plots show more variability and stronger FOUS-LF contrast than the results for middle-quintile weather. Surface temperature and VPD_max centroids indicate slightly greater growth response for LF. For T_sfc, most of the LFs had greater growth response than their companion FOUS; for VPD_max, the scatter of individual pairs is close to balanced across the diagonal. In contrast, RH_sfc, U_sfc, FFWI, and HDW_max all have more pairs that experienced greater growth for the individual FOUS than their LFs, and the centroids are distinctly above the diagonal, showing the mean response across fires to locally extreme weather is greater for FOUS than LFs.

\section{2) Aggregate growth Response}

Growth response for aggregated LF and FOUS days estimated at the 80th regression quantile is shown in Fig. 10. Figures 10a-f show the 80th regression quantile lines for each set of fires, bracketed by the lower bounds and upper bounds determined by $\mathrm{R}$, the bounds referred to here as an "estimate envelope." The graphs show that response to T_sfc and RH_sfc is very similar for both FOUS and LFs - the best estimate lines are very close together. For these two and VPD_max, the best estimates for the two fire sets are completely within each other's estimate envelopes. For the remaining weather measures, the

(a)

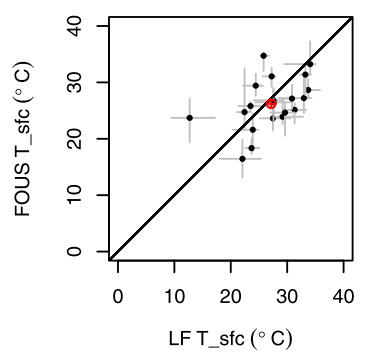

(c)

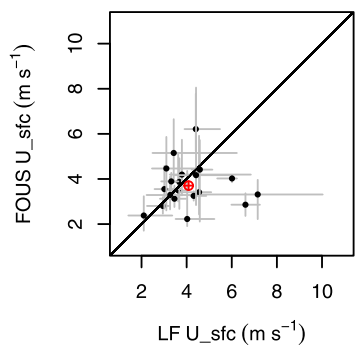

(e)

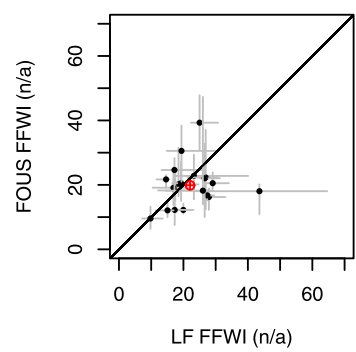

(b)

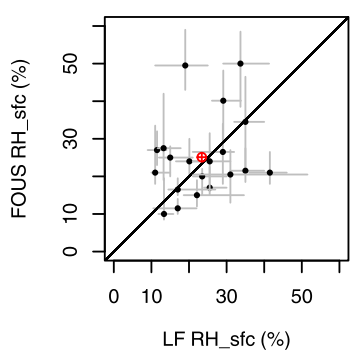

(d)

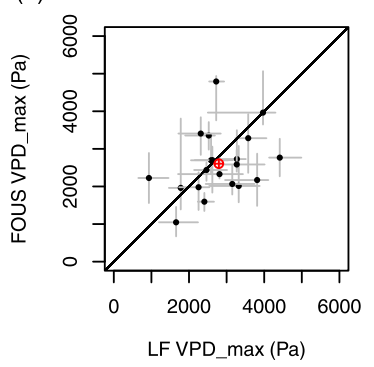

(f)

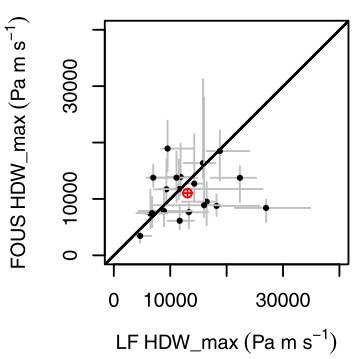

FIG. 6. Paired median values of (a) T_sfc, (b) RH_sfc, (c) U_sfc, (d) VPD_max, (e) FFWI, and (f) HDW_max. Solid black points indicate median (LF, FOUS) values. Crosshairs extend from the 25 th to the 75 th percentile for each fire. Red open circles with cross hairs indicate the centroid of the medians for all fires.

growth response for FOUS is greater than for LF, and the bestestimate lines lie outside one another's estimate envelopes over at least part of the range of weather values. The regressions for U_sfc, FFWI, and HDW_max show most clearly that FOUS growth responds more strongly to these weather properties than LF growth (i.e., the FOUS lines are above the LF lines), and that the marginal response of growth to increase in the weather property (slope) is greater for FOUS.

\section{3) OUTLIER GROWTH}

Our final test is how growth on weather outlier days compares with overall growth. Table 3 shows the results for each property and fire set (results for scaled linear growth, shown in Table 3, are discussed in the appendix). For several weather property-fire set combinations, there are no fires with any outliers. The FFWI has both the greatest outlier growth ratio of all weather properties for FOUS, and the largest difference in outlier growth ratio between FOUS and LF fires. The outlier growth ratio for FFWI during LFs is less than one, meaning 
(a)

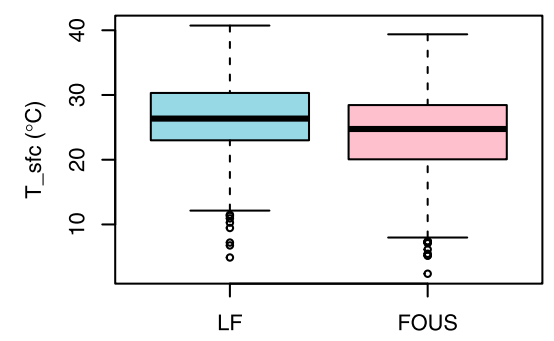

(c)

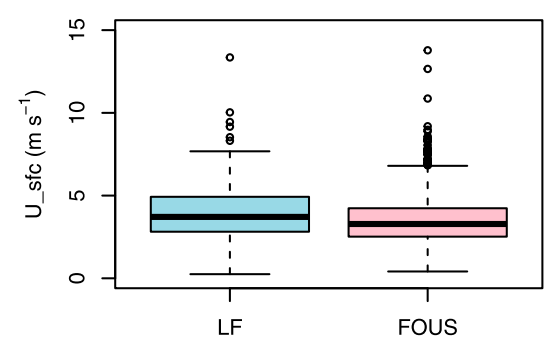

(e)

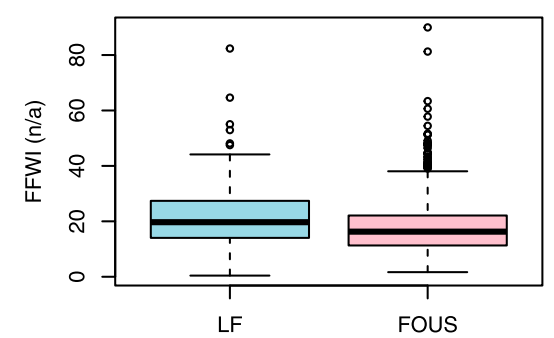

(b)

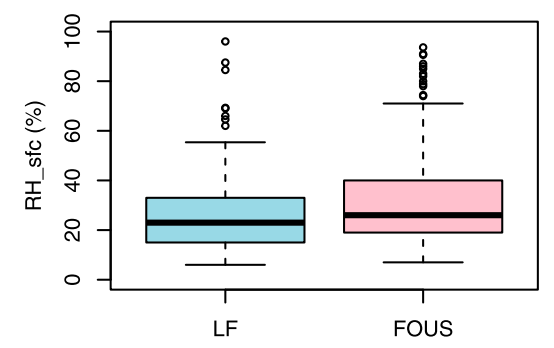

(d)

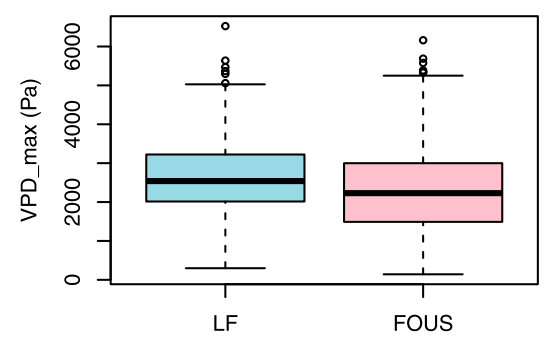

(f)

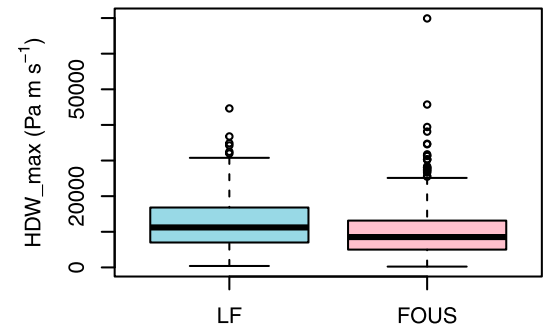

Fig. 7. Box-and-whisker plots for LF (blue) and FOUS (red): (a) T_sfc, (b) RH_sfc, (c) U_sfc, (d) VPD_max, (e) FFWI, and (f) HDW_max.

high FFWI days had below-average growth on those fires. There were eight FOUS and three LF with outlier FFWI days. There were no FOUS with outlier T_sfc or RH_sfc values, only two LFs with any T_sfc outliers and one LF with RH_sfc outliers. Growth of FOUS on outlier days for all weather properties except VPD_max was double to quadruple lifetime average growth. Growth ratio of LFs on outlier days for most of the weather properties was between 0.8 and 1.3 . The highest outlier growth for LFs was for HDW_sfc, at 2.0.

\section{Discussion}

The comparison of basic (nonweather) properties for FOUS and LFs yielded only one measure with a striking difference, and that was duration. Average daily growth (measured in hectares) is greater for FOUS than LF, indicating the greater final sizes more than compensate for these greater durations. Other measures - seasonality, number of growth spurts, and runs of growth spurts - did not appear to differ strongly between the two sets. The fire seasonality comparison does suggest that FOUS may burn later into the season than LF do. This could be affected by the timing of end-of-season precipitation, something we did not examine here. Longer FOUS durations may result from their size and growth, rather than their size and growth being a result of their long durations. Alternatively, precursor conditions or factors not considered here (e.g., fuel loads) may persist throughout the lifetime of the FOUS, but not the LFs. As such, we conclude that for these fires, duration and other basic characteristics are not direct causal factors distinguishing FOUS from LFs.

Antecedent evaporative demand, as measured by 2-week EDDI, showed higher values for most FOUS than their partner LFs. The 10-day sum of HDW_sfc, HDW10, showed less difference between the two fire sets, indicating aerodynamic moisture flux is insufficient alone to differentiate between the two types of fires. Other factors, such as insolation (included in EDDI), must be considered as well. Since EDDI does not consider precipitation directly, the results suggests that evaporative demand is a strong, potentially sufficient, factor driving FOUS.

Do daily weather properties differ between FOUS and LFs? Our tests consistently showed that median conditions for all weather properties considered are more moderate for FOUS than for LFs. FOUS had more fire-conducive outliers for moisture and wind than LF had. Do FOUS and LFs respond differently to comparable weather conditions? The two types of fires appear to respond similarly to moderate, middlequintile weather conditions. But when wind, FFWI, or HDW 
(a) T_sfc $\left({ }^{\circ} \mathrm{C}\right)$

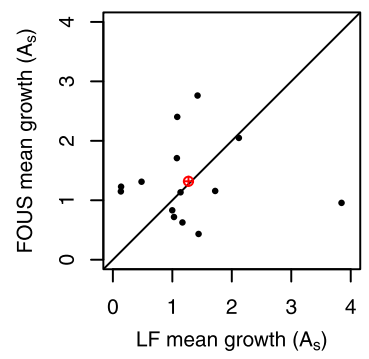

(c) U_sfc $\left(\mathrm{m} \mathrm{s}^{-1}\right)$

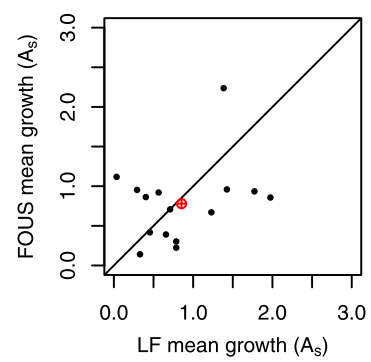

(e) FFWI (n/a)

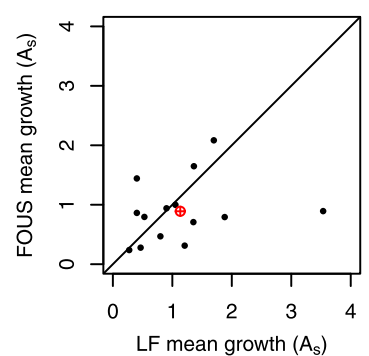

(b) RH_sfc (\%)

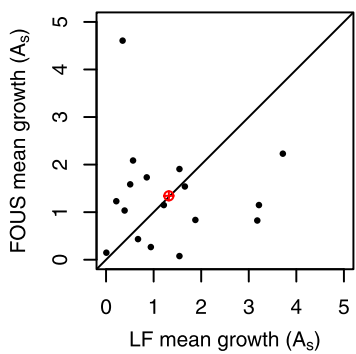

(d) VPD_max $(\mathrm{Pa})$

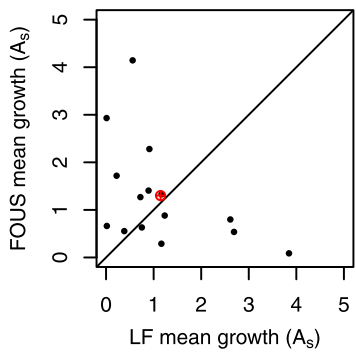

(f) HDW_max $\left(\mathrm{Pa} \mathrm{m} \mathrm{s}{ }^{-1}\right)$

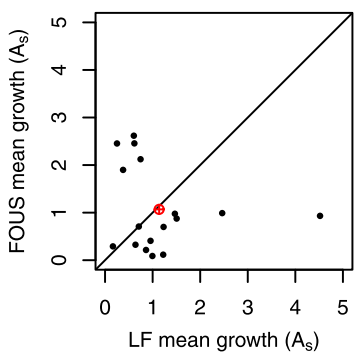

FIG. 8. Paired mean values of growth response, measured as scaled area $A_{s}$ for days when weather values were within the pairbased third quintile: (a) T_sfc, (b) RH_sfc, (c) U_sfc, (d) VPD_ max, (e) FFWI, and (f) HDW_max. The red open circle with cross hairs indicates the centroid of the means for all fires.

is at the higher end of its range, there is a greater difference between FOUS growth and LF growth. Our results show little difference in growth response between the two fire sets at high temperatures and low atmospheric moisture. There was little discernible difference between the growth responses for the three moisture measures: RH_sfc, VPD_sfc, and VPD_max.

Examining growth associated with outlier weather on individual fires indicated that growth on high wind speed days (and as a result high FFWI and HDW days) was above-average for both sets of fires, but was dramatically greater on outlier days for FOUS than for LFs. The indices FFWI and HDW appear to capture more of an amplification for FOUS than raw wind speed, suggesting that dry winds, in particular, play a role in separating FOUS from LFs.

Our study suggests that short-term antecedent evaporative demand sets the stage for FOUS. One way to look at this is that the antecedent atmospheric dryness results in fires burning more efficiently, so that for given daily weather conditions, the

(a) T_sfc $\left({ }^{\circ} \mathrm{C}\right)$

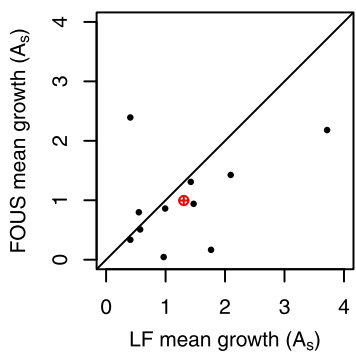

(c) U_sfc $\left(\mathrm{m} \mathrm{s}^{-1}\right)$

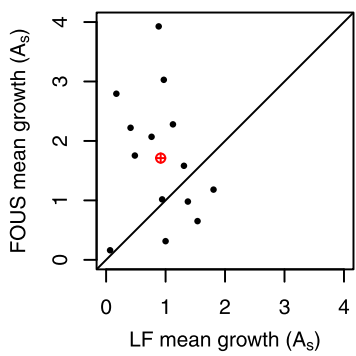

(e) $\quad F F W I(n / a)$

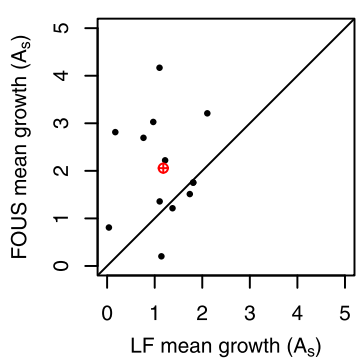

FIG. 9. As in Fig. 8, but for pair-based top-quintile weather conditions (bottom quintile for $\mathrm{RH} \_s f c$ ).

fire spreads more readily. It is then daily weather and most particularly individual days with strong, dry winds, that push a fire to become an FOUS instead of merely a LF. The results suggest that under these conditions, interaction effects or nonlinear influences become important in determining fire growth. On more typical weather days, FOUS and LFs grow comparably.

Direct comparison with Stavros et al. (2014) and Barbero et al. (2014) is not possible for two reasons. First, the size thresholds used for the larger fires in those studies were closer to those used for smaller fires (LFs) here, so there was no FOUS equivalent. Second, the use of 7-day averages and composite indices (such as many of the fire danger system components in various systems and countries) instead of basic weather properties (wind speed, temperature, atmospheric moisture) obscured the influence of any individual weather property. What can be said, however, is that the start-day and 7-day averages used in those studies would have only captured about half of the fires in this study. Ten of the 20 FOUS blew up in the first 7 days, meaning the rest were driven 
(a)

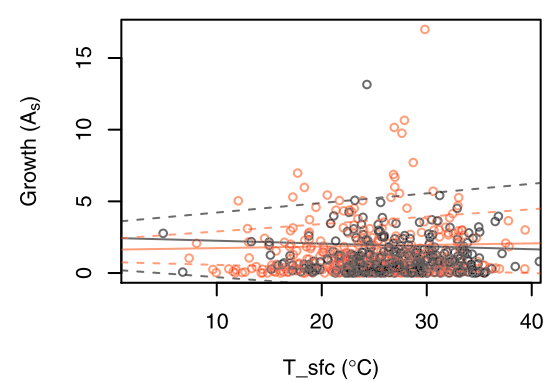

(c)

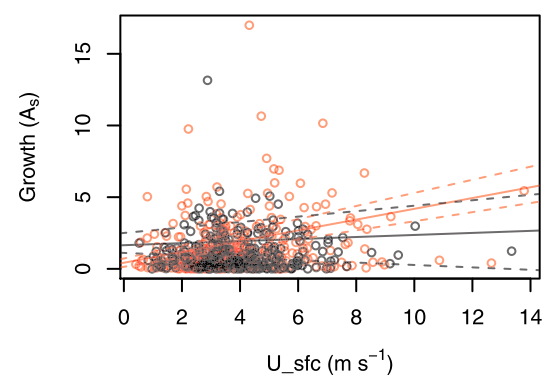

(e)

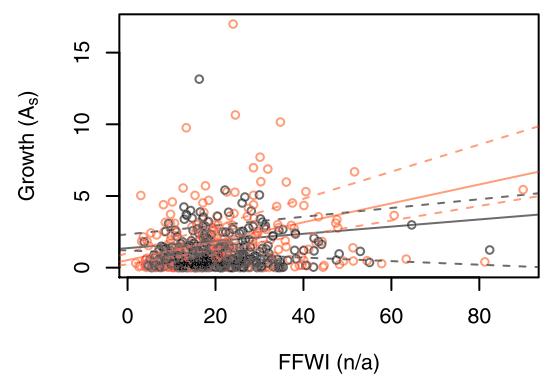

(b)

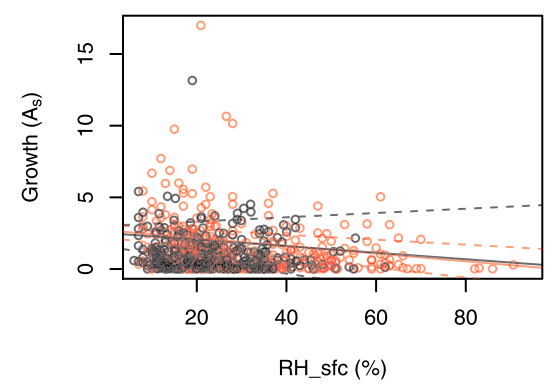

(d)

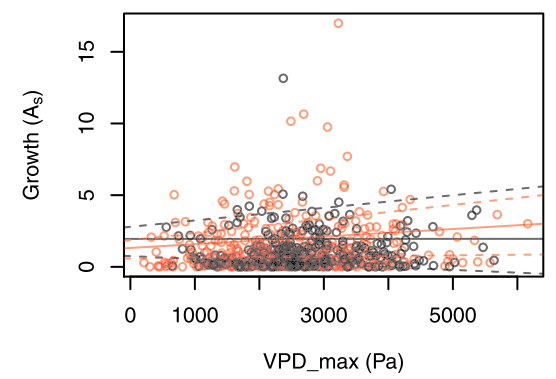

(f)

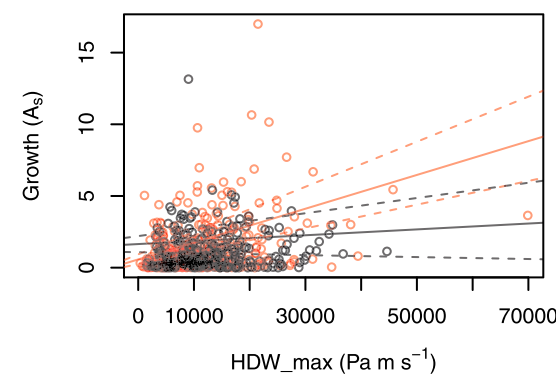

FIG. 10. Growth response to weather variables for aggregated FOUS (red) and LF (black) data. Open circles indicate daily values for fires in each set. Solid lines indicate the bestestimate linear fit at the 80th quantile. Dashed lines bracketing each solid line show the upper and lower bounds of slope and intercept as determined by R software.

by weather after that period, weather that would not have been reflected in a 7-day average at their start.

The results raise the question of whether projections of FOUS-like fires using future climate simulations (e.g., Barbero et al. 2015) capture the daily weather necessary to identify these fires. While antecedent evaporative demand may have numerically small spatial gradients, terrain influences wind speed at scales most climate models do not capture. Accurate downscaling may be essential to predicting the probability of these fires in the future.

We have treated other factors known to influence fire growth as part of the residuals, or noise, in our growth data. Our interest was the daily weather properties. None of our tests provides a quantitative measure of "variability explained," leaving that question unanswered. We believe our dataset is too small to yield a statistically reliable estimate of this, and a dataset incorporating more fires would be necessary.

Our results are consistent with the long-standing concept of "critical fire weather patterns," reviewed and summarized in
Werth et al. (2016). The four weather elements associated with critical fire weather patterns across geographic regions are drought, low relative humidity, strong wind, and atmospheric instability. The present study did not discuss instability, but the results are consistent with all three of the other factors.

Critical fire weather patterns are themselves closely tied to synoptic weather systems. These are well studied independent of fire, and there are many ways to quantify and describe their structures and life cycles. The general critical fire weather pattern characteristics are consistent with high pressure systems (pressure ridges) creating light winds, clear skies and little or no precipitation, followed by a low pressure system (cold front, or "breakdown of the upper-level ridge" in common fire-weather usage) moving through to bring strong winds, instability, and low relative humidity. If the frontal system's passage is brief and the ridge resumes, this would be consistent with the antecedent evaporative demand, the strong, dry winds, and the overall lighter mean winds that this study found correspond to FOUS. If, however, the ridge did not rebuild behind the 
TABLE 3. Ratio of growth on outlier days to lifetime-average growth across all fires in each set. The number of fires with outliers for a given weather property is provided, since not every fire had outlier days for any given weather property. Results for area growth and scaled linear growth are discussed in the appendix. (Outlier growth for area growth is mathematically identical to that for scaled area growth.)

\begin{tabular}{|c|c|c|c|c|c|c|}
\hline \multirow[b]{2}{*}{ Variable } & \multirow[b]{2}{*}{ No. FOUS } & \multirow[b]{2}{*}{ No. LFs } & \multicolumn{2}{|c|}{ (Scaled) area growth } & \multicolumn{2}{|c|}{ Scaled linear growth } \\
\hline & & & FOUS ratio & LF ratio & FOUS ratio & LF ratio \\
\hline T_sfc & 0 & 2 & - & 0.51 & - & 1.5 \\
\hline RH_sfc & 0 & 1 & - & 0.06 & - & 0.03 \\
\hline U_sfc & 6 & 3 & 3.6 & 1.1 & 3.6 & 1.2 \\
\hline U_max & 8 & 4 & 2.0 & 1.3 & 1.8 & 1.8 \\
\hline VPD_max & 1 & 1 & 0.71 & 0.80 & 0.73 & 2.8 \\
\hline FFWI & 8 & 3 & 4.0 & 0.86 & 4.7 & 1.4 \\
\hline HDW_max & 10 & 4 & 3.1 & 1.1 & 3.2 & 1.3 \\
\hline HDW_sfc & 11 & 3 & 3.3 & 2.0 & 4.1 & 3.2 \\
\hline
\end{tabular}

frontal passage, the prevailing conditions would be somewhat stronger winds and higher relative humidity. This latter type of synoptic progression would produce mean values of these variables more similar to what was seen for LFs. Failure of the ridge to return could be a hallmark of LF patterns.

The growth associated with top-quintile weather conditions, and with weather outliers, could be better compared and understood with a more comprehensive point-by-point climatology. This would better identify quantiles for weather at any location and show how weather during these fires compared with more general conditions in the area.

One of the most challenging parts of working with operational fire growth records is administrative complexes-when multiple fires are grouped together for records and management purposes. These fires may or may not burn into each other, and the records do not always contain enough information about this, or about the addition or removal of fires from the complex. It may be necessary to refine the definition of FOUS to address complexes.

\section{Conclusions}

The challenges of using operational fire growth data and combining multiple fires in a meaningful way are major obstacles to this kind of study. The consistency of our results shows that these obstacles are not insurmountable, however. At the very least, this analysis and similar studies can highlight relationships for further investigation and more physically based study.

The results suggest several areas for further work: investigate instability, the fourth component of critical fire weather patterns (presently underway); examine a broader climatology to improve the context of "outliers"; study whether precipitation is important to ending fires of unusual size; and of course, see whether these results bear up in further analysis with different fires. In addition to these, work is presently underway looking at details of the winds-zonal and meridional components, and changes in speed and direction from the previous day-to see whether more specific characteristics than just speed influence fires of unusual size.

One of the major outstanding questions is how fuels affect fires of unusual size. Total fuel mass in a given area is stable over the lifetime of a fire, but varies greatly in space-across the mosaic of grass, savannah, scrub, beetle-killed timber, etc.
Temporal moisture fluctuations due to diurnal cycles, precipitation, and spatial variations due to terrain slope and aspect change the effectively available fuel and energy release, and thus the rate of spread during combustion. Any study examining this will require detailed fuel load and moisture data for all locations within each fire's perimeter, over each fire's duration.

The synoptic development of critical fire weather patterns, and the weather properties this study highlights, are generally understood. Specifics of how large-scale ridges and short-wave troughs interact, and their persistence or transient nature, appear to be important in differentiating fires of unusual size from large fires. Synoptic dynamics is a mature scientific field, while "critical fire weather patterns" are still rooted in terminology and research from the 1960s. The three-dimensional, time-varying nature of synoptic patterns needs to be recognized so that fire meteorologists can better understand which patterns are more or less cause for concern.

Relatively rare or extreme events such as growth associated with outlier and upper-quintile weather are a small percentage of the overall data that go into developing numerical or theoretical growth models. Our results suggest that these models may underestimate these growth events, simply due to their rarity. The importance of these fires and growth events requires determination of the degree to which this is true, so that managers, scientists, and the public understand when the models may no longer be applicable or accurate.

Several of these potential avenues require additional, highquality daily fire growth data. This is rare, and requires no small amount of human labor to reconcile. The 2020 fire season may prove a windfall, however. A preliminary count indicates there were 30 fires that grew large enough to possibly be fires of unusual size. If, after quality control and reconciliation, even 20 of these qualify, that will be as many fires from 1 year as our project gathered from an earlier 15-yr period.

Acknowledgments. This work was supported solely by the authors' institutional funding. The authors thank Dr. Kara Yedinak for detailed review of the draft paper and Drs. Yedinak and Jay Charney for extensive conversations and insight during the study. Two anonymous reviewers provided exceptionally helpful comments and insights during the review process, and we thank them also. 
(a) T_sfc $\left({ }^{\circ} \mathrm{C}\right)$

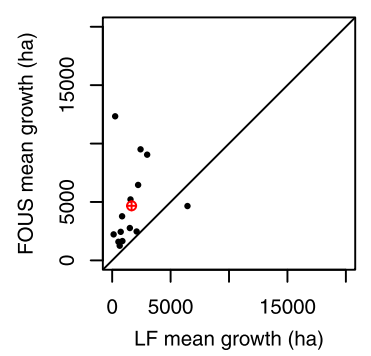

(c) U_sfc $\left(\mathrm{m} \mathrm{s}^{-1}\right)$

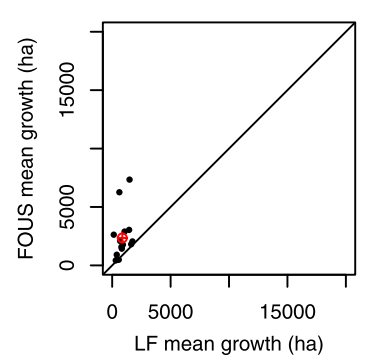

(e) $\quad F F W I(n / a)$

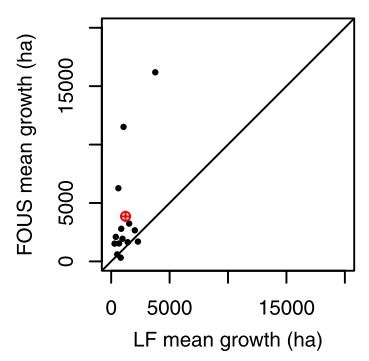

(b) RH_sfc (\%)

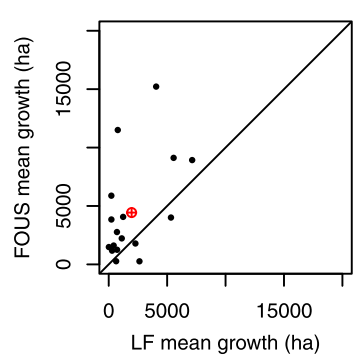

(d) VPD_max (Pa)

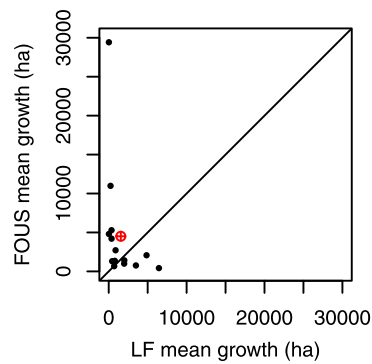

(f) HDW_max $\left(\mathrm{Pa} \mathrm{m} \mathrm{s}^{-1}\right)$

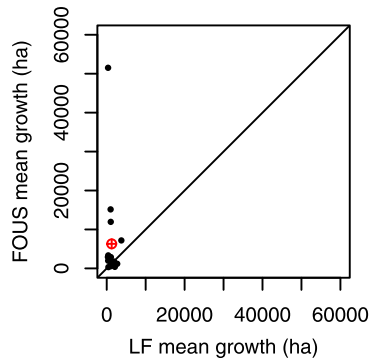

FIG. A1. Paired mean values of growth response, measured as unscaled area $A$ for days when weather values were within the pairbased third quintile: (a) T_sfc, (b) RH_sfc, (c) U_sfc, (d) VPD_ max, (e) FFWI, and (f) HDW_max. The red open circle with cross hairs indicates the centroid of the means for all fires.

\section{APPENDIX}

\section{Results Using Unscaled Area and Scaled Linear Growth}

The growth response analyses reported in the main body of the paper used growth measured in scaled area $A_{s}$. The same comparisons between FOUS and LF growth responses were performed using area growth and scaled linear growth $L_{s}$ as defined in Eq. (2). We present these results here. Because the primary purpose of this appendix is to compare and contrast results for different growth measures, we do this in each section rather than presenting the $A$ and $L_{s}$ results first and following with a discussion of specific differences after that.

\section{a. Area growth response to weather}

Figures $\mathrm{A} 1-\mathrm{A} 3$ show results measuring response in area $A$ (ha), analogous to Figs. 8-10 in the main body. For moderate (third quintile; Fig. A1) weather conditions, growth on the majority of FOUS exceeds that on their paired LF for all of the

(a) T_sfc $\left({ }^{\circ} \mathrm{C}\right)$

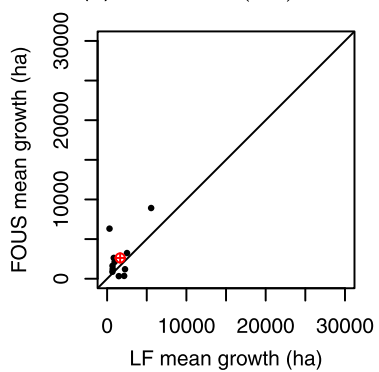

(c) U_sfc $\left(\mathrm{m} \mathrm{s}^{-1}\right)$

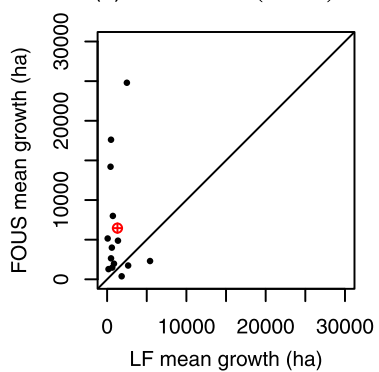

(e) $\quad F F W I(n / a)$

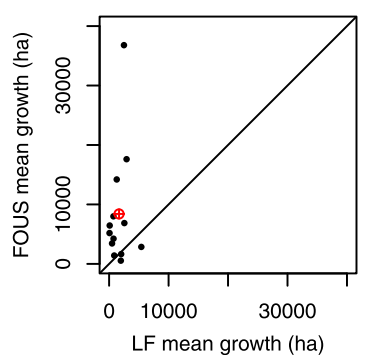

(b) RH_sfc (\%)

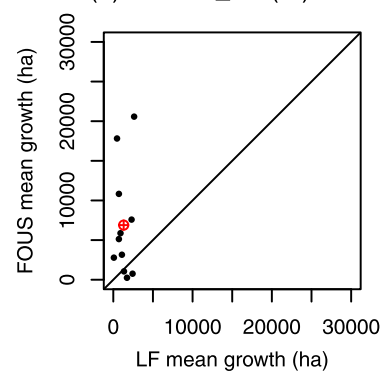

(d) VPD_max (Pa)

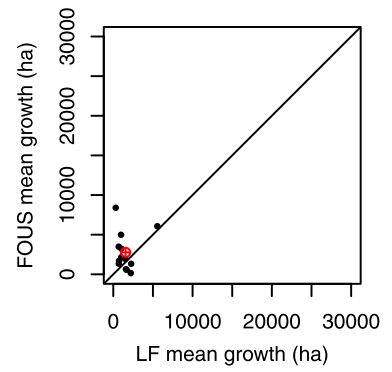

(f) HDW_max $\left(\mathrm{Pa} \mathrm{m} \mathrm{s}{ }^{-1}\right)$

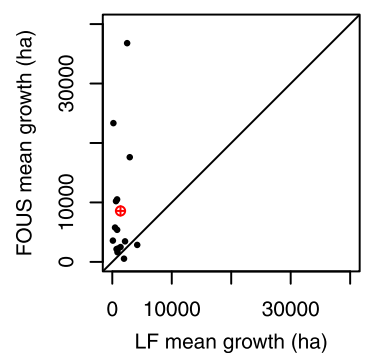

FIG. A2. As in Fig. A1, but for pair-based top-quintile weather conditions (bottom quintile for RH_sfc).

weather properties except VPD_max. Mean growth over all pairs, indicated by the red crossed circle, is greater for FOUS than for LFs for all weather properties considered, with the smallest difference for HDW_max. This contrasts with results when growth is measured in scaled area, where the weather properties elicited very similar growth for both FOUS and LF and scatter of pairs was more balanced across the diagonal.

When more fire-conducive weather is considered (fifth quintile for all measures but $\mathrm{RH}_{\text {s }} \mathrm{sfc}$, for which this is first quintile; Fig. A2) and compared with the third quintile, there are more pairs that fall on the LF side of the diagonal for T_sfc, U_sfc, and FFWI but fewer pairs for VPD_max and HDW_ max. Mean growth response for T_sfc over all pairs is more similar than it was for third-quintile conditions (Fig. A1a vs Fig. A2a). The growth response for members of FOUS and LF pairs, in response to third- or fifth-quintile VPD_max (Figs. A1d, A2d), is very similar. For the other weather properties, the difference between FOUS growth response and LF growth response is greater in the fifth weather quintile than it was in the third quintile. (Axes have changed between 
(a)

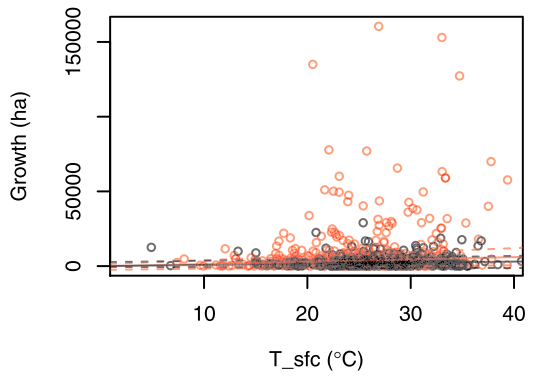

(c)

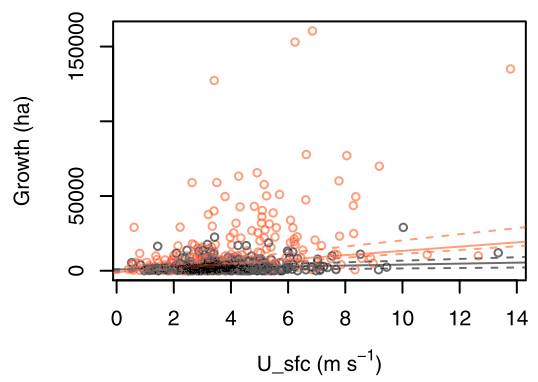

(e)

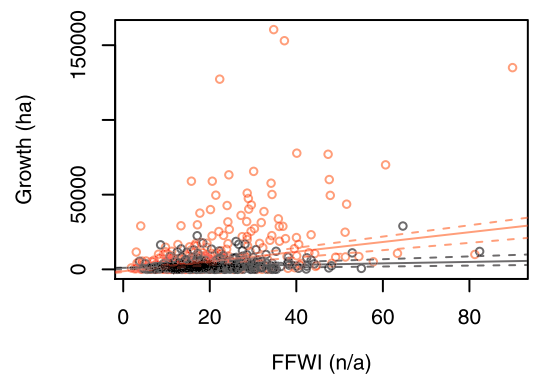

(b)

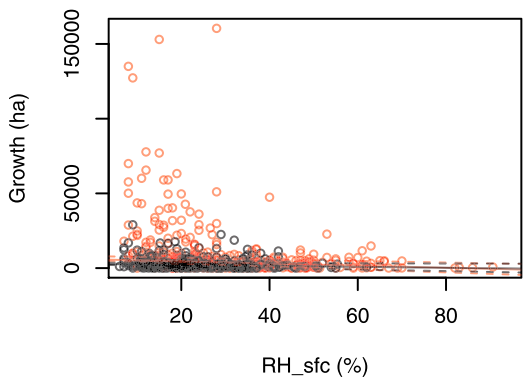

(d)

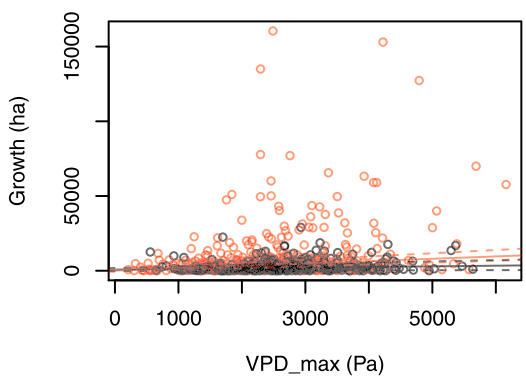

(f)

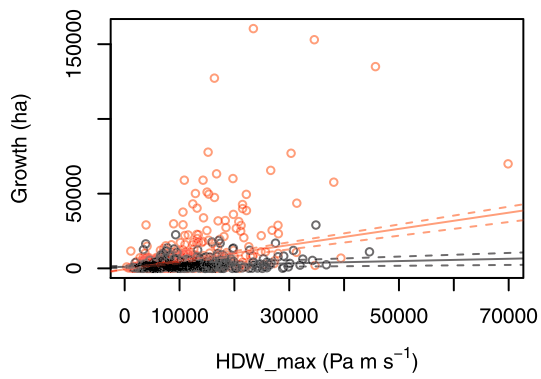

FIG. A3. Growth response to weather variables for aggregated FOUS (red) and LF (black) data. Open circles indicate daily values for fires in each set. Solid lines indicate the bestestimate linear fit at the 80th quantile. Dashed lines bracketing each solid line show the upper and lower bounds of slope and intercept as determined by $\mathrm{R}$ software.

Figs. A1 and A2 to accommodate growth differences between the two weather quintiles.) For all weather properties, the centroid indicates mean growth over all pairs is greater for the FOUS than for the LFs.

When we aggregated all the fire days within each set and examined the 80th regression quantile (Fig. A3), the FOUS and LF regressions are very similar for $\mathrm{T}_{-}$sfc, and for RH_sfc. For both measures the estimate envelopes for LF and FOUS bracket the other set's best estimate. For all of the other tested weather properties, however, the separation of envelopes is clearly visible. The smallest separation is VPD_max, where the lower bound of the FOUS envelope closely matches the upper bound of the LF envelope at high VPD_max values. The separation of the envelopes for U_sfc, VPD_max, FFWI, and HDW_max is much more distinct when growth is measured in area, than in scaled area.
Outlier growth for area is mathematically identical to that for scaled area (Table 3).

\section{b. Linear-scaled growth response to weather}

Linear-scaled growth responses to pair middle-quintile weather (Fig. A4) appears very similar to $A_{s}$ response (Fig. 8). Pairs are scattered across the diagonal, indicating that for some pairs FOUS growth response exceeded LF growth response to middle-quintile weather, but for other pairs the reverse was true. The centroids are all very close to the diagonal suggesting that on average, there is little or no difference in growth response between the two fire sets.

Fire-conducive fifth-quintile (first quintile for RH_sfc) growth response, presented in Fig. A5, shows little difference from scaled-area growth response for RH_sfc, U_sfc, FFWI, and HDW_max. The FOUS growth response exceeds LF response for 
(a) T_sfc $\left({ }^{\circ} \mathrm{C}\right)$

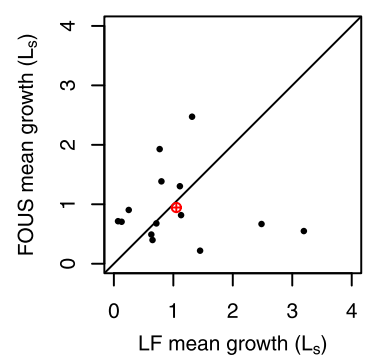

(c) U_sfc $\left(\mathrm{m} \mathrm{s}^{-1}\right)$

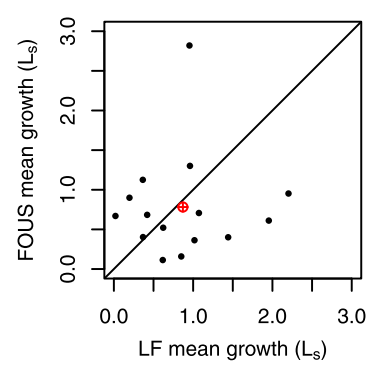

(e) $\quad F F W I(n / a)$

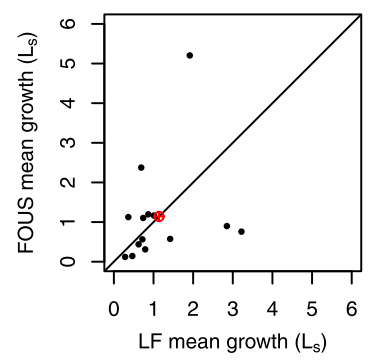

(b) $\mathrm{RH} \_$sfc (\%)

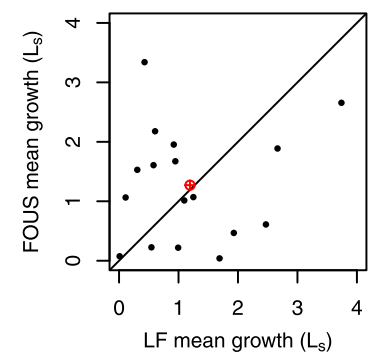

(d) VPD_max $(\mathrm{Pa})$

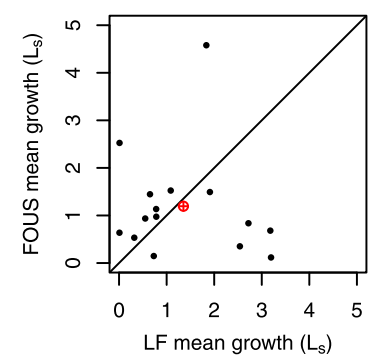

(f) HDW_max $\left(\mathrm{Pa} \mathrm{m} \mathrm{s}{ }^{-1}\right)$

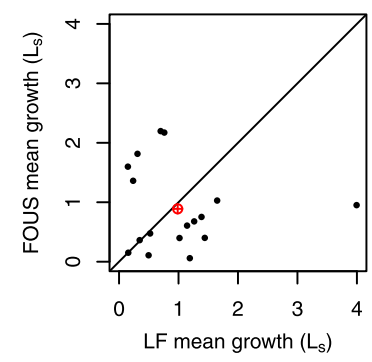

FIG. A4. As in Fig. A1, but with growth response measured as scaled linear growth $L_{s}$ for days when weather values were within the pair-based third quintile.

most, but not all, pairs, and the centroids are above the diagonal. For T_sfc and VPD_max, $L_{s}$ growth response is greater among FOUS than LF, while the reverse was true using $A_{s}$.

Eightieth-quantile regressions on the aggregated data (Fig. A6) are generally similar to the regressions for the same weather properties using $A_{s}$. Regressions for U_sfc, VPD_max, FFWI, and HDW_max show more overlap in their estimated envelopes for $L_{s}$ than they did for $A_{s}$, suggesting the FOUS and LF growth responses measured as $L_{s}$ may be similar.

Outlier growth results using $L_{s}$ (Table 3) are generally similar to those using $A_{s}$. The contrast between FOUS and LF outlier growth ratios is greatest for U_sfc and the derived indices, specifically FFWI and HDW_max. There are too few fires or outliers to reliably draw any conclusions about T_sfc, RH_sfc, or VPD_max.

\section{c. Growth measure discussion}

When growth response is measured in area, FOUS grow more than LF for median and fire-conducive weather conditions-as

(a) T_sfc $\left({ }^{\circ} \mathrm{C}\right)$

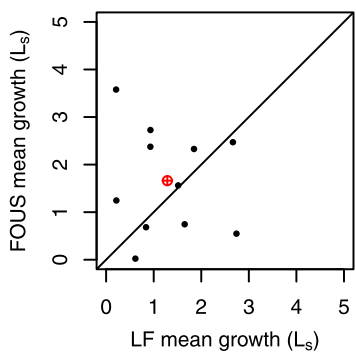

(c) U_sfc $\left(\mathrm{m} \mathrm{s}^{-1}\right)$

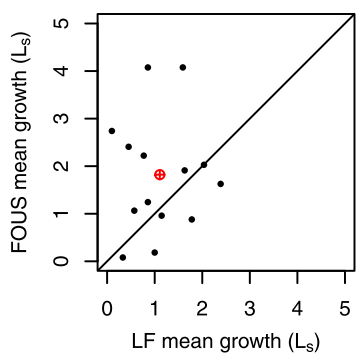

(e) $\quad F F W I(n / a)$

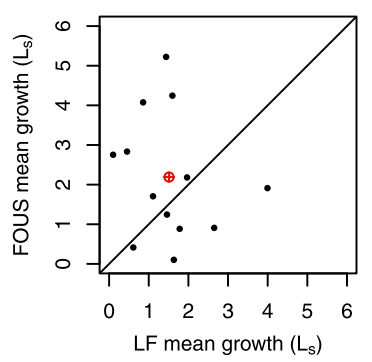

FIG. A5. As in Fig. A4, but for pair-based top-quintile weather conditions (bottom quintile for RH_sfc).

well as for fire-moderate first-quintile conditions (not shown). In other words, FOUS area grows more than LF area across the observed range of all of the weather properties. The 80thquantile regressions for T_sfc, RH_sfc, and VPD_max are similar for the two types of fires and show very little slope for either set, suggesting area growth responds weakly to these properties and no differently for the two sets of fires. Overall, the results suggest that FOUS outgrow LF in terms of area on a daily basis, regardless of weather conditions. The margin between FOUS and LF growth is greater when winds are stronger, however.

Measuring growth using $L_{s}$ produces results very similar to those for $A_{s}$. Growth under moderate weather conditions is very similar for FOUS and LFs, growth under fire-conducive conditions is slightly greater for FOUS than LFs. Quantile regression envelopes again overlap heavily, and best fit lines have similar slopes, for T_sfc, RH_sfc, and VPD_max. Estimate envelopes for U_sfc, FFWI, and HDW_max are more separated than they were for the latter weather properties, and the FOUS best estimates have steeper slopes than the LF best estimates-again similar to the $A_{s}$ results. The 
(a)

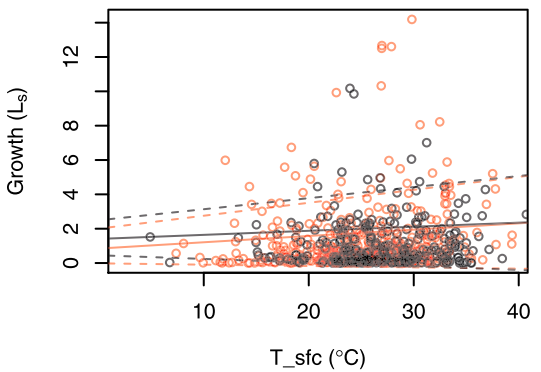

(c)

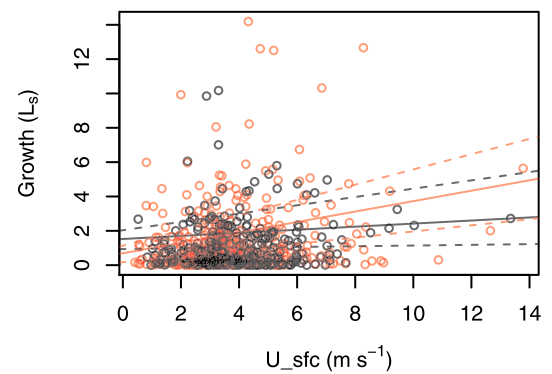

(e)

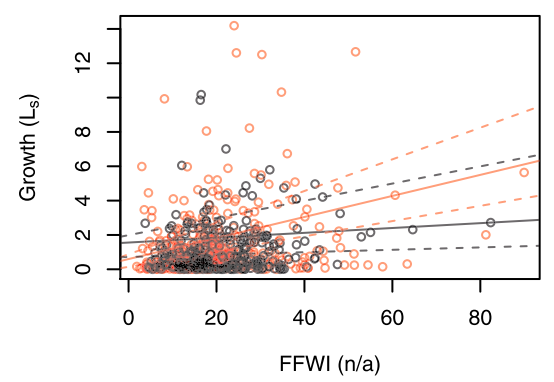

(b)

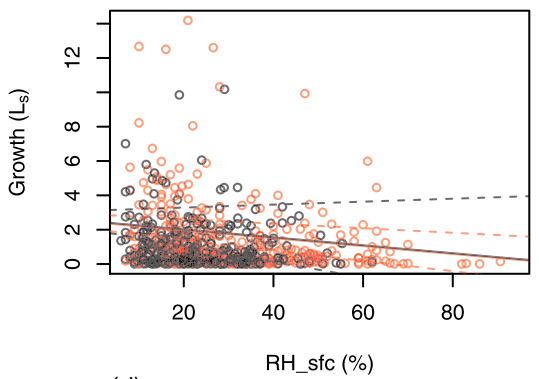

(d)

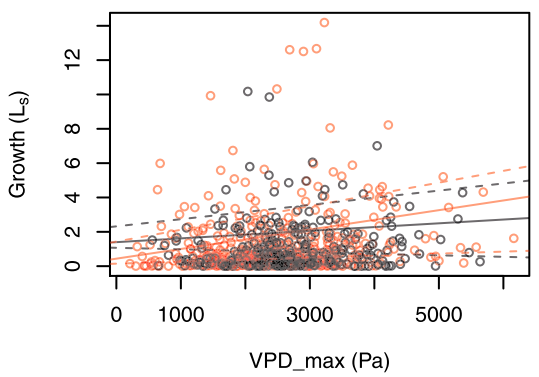

(f)

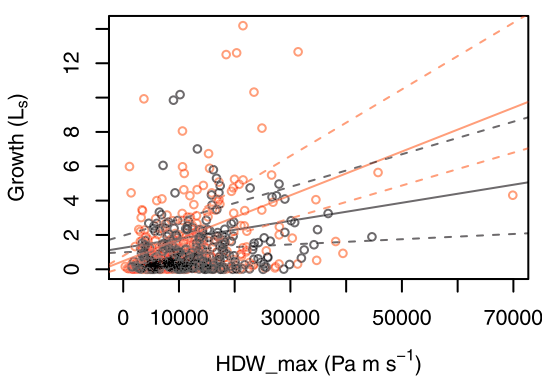

FIG. A6. As in Fig. A3, but growth response is measured using scaled linear growth $L_{s}$.

most notable difference from the scaled area results is that the estimate envelopes are wider for the wind and index measures using $L_{s}$, resulting in more overlap.

Overall, wind and the indices (FFWI and HDW_max) have stronger FOUS growth responses for all three growth measures, and temperature, relative humidity, and vapor pressure have more comparable effects on the two sets of fires' growth. The disparity between FOUS and LF growth response is more apparent for unscaled area and least apparent for scaled linear growth.

\section{REFERENCES}

Abatzoglou, J. T., and C. A. Kolden, 2011: Relative importance of weather and climate on wildfire growth in interior Alaska. Int. J. Wildland Fire, 20, 479-486, https://doi.org/10.1071/ WF10046.

Balling, R. C., G. A. Meyer, and S. G. Wells, 1992: Relation of surface climate and burned area in Yellowstone National Park. Agric. For. Meteor., 60, 285-293, https://doi.org/10.1016/ 0168-1923(92)90043-4.

Barbero, R., J. T. Abatzoglou, E. A. Steel, and N. K. Larkin, 2014: Modeling very large fire occurrences over the continental
United States from weather and climate forcing. Environ. Res. Lett., 9, 124009, https://doi.org/10.1088/1748-9326/9/12/124009. ,-- N. K. Larkin, C. A. Kolden, and B. Stocks, 2015: Climate changes presents increased potential for very large fires in the contiguous United States. Int. J. Wildland Fire, 24, 892-899, https://doi.org/10.1071/WF15083.

Brown, T., S. Leach, B. Wachter, and B. Gardunio, 2020: The extreme 2018 northern California fire season [in "Explaining Extreme Events of 2018 from a Climate Perspective"]. Bull. Amer. Meteor. Soc., 101 (1), S1-S4, https://doi.org/10.1175/ BAMS-D-19-0275.1.

Cade, B. S., J. W. Terrell, and R. L. Schroeder, 1999: Estimating effects of limiting factors with regression quantiles. Ecology, 80, 311-323, https://doi.org/10.1890/0012-9658(1999)080[0311: EEOLFW]2.0.CO;2.

Coen, J. L., E. N. Stavros, and J. A. Fites-Kaufman, 2018: Deconstructing the King megafire. Ecol. Appl., 28, 1565-1580, https://doi.org/10.1002/eap.1752.

Cruz, M. G., A. L. Sullivan, J. S. Gould, N. C. Sims, A. J. Bannister, J. J. Hollis, and R. J. Hurley, 2012: Anatomy of a catastrophic wildfire: The Black Saturday Kilmore East fire in Victoria, Australia. For. Ecol. Manage., 284, 269-285, https://doi.org/ 10.1016/j.foreco.2012.02.035. 
Fosberg, M. A., 1978: Weather in wildland fire management: The fire weather index. Proc. Conf. on Sierra Nevada Meteorology, Lake Tahoe, CA, Amer. Meteor. Soc. and USDA Forest Service, 1-4.

Hobbins, M. T., A. Wood, D. J. McEvoy, J. L. Huntington, C. Morton, M. Anderson, and C. Hain, 2016: The evaporative demand drought index. Part I: Linking drought evolution to variations in evaporative demand. J. Hydrometeor., 17, 17451761, https://doi.org/10.1175/JHM-D-15-0121.1.

Holden, Z. A., and Coauthors, 2018: Decreasing fire season precipitation increased recent western US forest wildfire activity. Proc. Natl. Acad. Sci. USA, 115, E8349-E8357, https://doi.org/ 10.1073/pnas.1802316115.

Larkin, N. K., and Coauthors, 2015: Future megafires and smoke impacts. Joint Fire Science Program Rep., 104 pp., https:// www.firescience.gov/projects/11-1-7-4/project/11-1-7-4_final_ report.pdf.

Littell, J. S., D. McKenzie, D. L. Peterson, and A. L. Westerling, 2009: Climate and wildfire area burned in western U.S. ecoprovinces, 1916-2003. Ecol. Appl., 19, 1003-1021, https:// doi.org/10.1890/07-1183.1.

McEvoy, D. J., M. Hobbins, T. J. Brown, K. VanderMolen, T. Wall, J. L. Huntington, and M. Svoboda, 2019: Establishing relationships between drought indices and wildfire danger outputs: A test case for the California-Nevada drought early warning system. Climate, 7, 52, https://doi.org/10.3390/cli7040052.

- D. W. Pierce, J. F. Kalansky, D. R. Cayan, and J. T. Abatzoglou, 2020: Projected changes in reference evapotranspiration in California and Nevada: Implications for drought and wildland fire danger. Earth's Future, 8, e2020EF001736, https://doi.org/ 10.1029/2020EF001736.

Nauslar, N., T. J. Brown, D. J. McEvoy, and N. Lareau, 2019: Record setting 2018 California wildfires [in "State of the Climate in 2018"]. Bull. Amer. Meteor. Soc., 100 (9), S195S196, https://doi.org/10.1175/2019BAMSStateoftheClimate.1.

Peterson, D. A., E. J. Hyer, J. R. Campbell, M. D. Fromm, J. W. Hair, C. F. Butler, and M. A. Fenn, 2015: The 2013 Rim Fire implications for predicting extreme fire spread, pyroconvection, and smoke emissions. Bull. Amer. Meteor. Soc., 96, 229-247, https://doi.org/10.1175/BAMS-D-14-00060.1.
Potter, B. E., 2018: Quantitative evaluation of the Haines index's ability to predict fire growth events. Atmosphere, 9, 177, https://doi.org/10.3390/atmos9050177.

— S. L. Goodrick, A. L. Srock, and J. J. Charney, 2015: Evaluation of a suite of simple fire weather indices for the 2014 fire season in the Pacific Northwest. 11th Symp. on Fire and Forest Meteorology, Minneapolis, MN, Amer. Meteor. Soc.,2.4., https://ams.confex.com/ams/11FIRE/webprogram/ Paper272191.html.

R Core Team, 2018: R: A language and environment for statistical computing. R Foundation for Statistical Computing, https:// www.R-project.org/.

Riley, K. L., J. T. Abatzoglou, I. C. Grenfell, A. E. Klene, and F. A. Heinsch, 2013: The relationship of large fire occurrence with drought and fire danger indices in the western USA, 19842008: The role of temporal scale. Int. J. Wildland Fire, 22, 894909, https://doi.org/10.1071/WF12149.

Sedano, F., and J. T. Randerson, 2014: Multi-scale influence of vapor pressure deficit on fire ignition and spread in boreal forest ecosystems. Biogeosci., 11, 3739-3755, https://doi.org/ 10.5194/bg-11-3739-2014.

Srock A. F., J. J. Charney, B. E. Potter, and S. L. Goodrick, 2018: The hot-dry-windy index: A new fire weather index. Atmosphere, 9, 279, https://doi.org/10.3390/atmos9070279.

Stavros, E. N., J. Abatzoglou, N. K. Larkin, D. McKenzie, and E. A. Steel, 2014: Climate and very large wildland fires in the contiguous western USA. Int. J. Wildland Fire, 23, 899-914, https://doi.org/10.1071/WF13169.

Tedim, F., and Coauthors, 2018: Defining extreme wildfire events: Difficulties, challenges, and impacts. Fire, 1, 9, https://doi.org/ 10.3390/fire1010009.

Wasserstein, R. L., and N. A. Lazar, 2016: The ASA statement on p-values: Context, process, and purpose. Amer. Stat., 70, 129133, https://doi.org/10.1080/00031305.2016.1154108.

Werth, P. A., and Coauthors, 2016: Synthesis of knowledge of extreme fire behavior: Volume 2 for fire behavior specialists, researchers, and meteorologists. General Tech. Rep. PNW-GTR-891, 258 pp., https://doi.org/10.2737/PNWGTR-891. 